\title{
The Analysis of Errors in Translation of Scientific Text from English to Indonesian Language
}

\author{
Mardin Silalahi ${ }^{1)}$, Zainal Rafli $^{2)}$, Yumna Rasyid ${ }^{3)}$ \\ 1) Simalungun University, Pematangsianta, Indonesia \\ E-mail: mards766@gmail.com \\ 2) State University of Jakarta, Jakarta, Indonesia \\ E-mail: zainal.rafli@unj.ac.id \\ 2) State University of Jakarta, Jakarta, Indonesia \\ E-mail: yumna.rasyid@unj.ac.id
}

\begin{abstract}
This study aims to find errors in the translation of scientific texts from English into Indonesian. This research uses the qualitative method with content analysis approach. The results showed that (1) the translation strategy, the majority of students used semantic strategy, especially modulation in translating scientific texts and at least used the special structural strategies of addition, (2) lexical error, the majority of students made formal lexical errors in word selection and the least (3) morphological errors, the majority of students make mistakes in the affixation field of improper use of affixation and the least of which are affixations that are not broken, (4) syntactic errors, syntactical errors found in the translation of scientific texts in the fields, phrases, clauses and sentences but the majority of students make mistakes in the field of sentences are the use of illogical phrases and the fewest errors in the field clause is the addition of auxiliary verbs in the equational or nominal clause, and the separation of the perpetrator (subject) and the word in the active clause, (5) the factor causing errors in translation ie the majority of students do not understand the source language text and the least of which is the quality of the source language using the incorrect grammatical, the sentence is vague, the idea is not coherent and many fungtuations.
\end{abstract}

Keywords: Error; Translation; Scientific Texts

\section{INTRODUCTION}

Translating a text from the source language (BSu) into the target language (BSa) requires its main skills in grammatical mastery and the selection of methods and appropriate strategies to produce translations that match the original intent and meaning of the source language (BSu). The mastery of improper application of methods and strategies and the inability to understand the grammar of the source language (BSu) then it is certain that the translation will not be maximal because of lexical errors such as morphology and syntax.

Basically as a diversion of meaning from the source language $(\mathrm{BSu})$ into the target language $(\mathrm{BSa})$. In this case, the transfer of meaning made from the first language form (source language) into the form of a second language (target language) through its semantic structure. Transferred meanings must be maintained, while the form may change.

In the process of selecting the meaning of each word in translation, it should take into account the meaning of the text of the source language ((BSu) so as not to get out of its original meaning when translated into the target language (BSa).In addition, in word selection to find common meaning when translated is quite difficult because there is a difference in terms of word form, structure, and style of language.This is because the meaning is not found in the target language (BSa).In the translation of the language of scientific texts, especially in research, there are several investigated among them: translation strategies, lexical errors, errors morphology, syntactic errors and factors 
causing mistakes in translation. Therefore the researcher reasoned to conduct research on "Error in Translation of Scientific Text from English into Indonesian (Research Content Analysis In Students FKIP University HKBP Nommensen Pematangsiantar).

\section{Translation}

Translation is a process based on the meaning of the text of the first language into a second language. The concept of translation should be able to use the vocabulary, grammatical structure, communication situation, and cultural context of the source language into the target language appropriately. Neither does Rasmieh Al-Amer et. al (2015: 1) that as the translation is an interpretive process and not merely a direct message transfer from a source language to a target language, the translator needs to systematically and accurately capture the full meaning of the spoken language. Translation is a delivery of messages from the source language into the target language, the translation needs to systematically and accurately capture the full meaning of the source language.

Based on the results of research conducted by Lea B. Jost et. al, (2017: 1) that the translation is a demanding process during which a message is analyzed, translated and communicated from one language to another. Translation is demanding the process by which messages are analyzed, translated and communicated from the source language into the target language. In connection with that opinion, Munday (2008: 10) states that the science of translation in general consists of pure and applied translations. Translation as a communication process. As according to Porta et. al, (2014: 788) that the translation helps people to communicate across linguistic and cultural barriers. Translation helps one to communicate with different cultures through language. Translation stands between two languages.

From the above definition, the meaning is the ultimate goal of the translation process to recreate the message from the source language $(\mathrm{BSu})$ into the target language (BSa). However, the translator in terms of reinventing the message should look for a grammatical or lexical equivalence.

Translation Strategy

Translation strategies are needed in translation because they relate to the way translators translate scientific texts. In addition to strategies in translation, there are also methods of translation, translation procedures, and translation techniques.

According to Kardimin (2013: 78) that the translation strategy is a translator's tactic to translate a word or group of words, or perhaps full sentences when the sentence can be broken down into smaller units for translation. According to research conducted by Nefedovaa (2014: 243) that cognitive strategies are used according to the in-built context-frame structure of the text. The cognitive strategy is used by the translator because it is seen as a tool for understanding the structure of the text. Translation strategies can be divided into two main types. First, the structural strategy is a strategy with respect to sentence structure.

Error
Error is an error in language usage due to speaker or writer violating rules or grammar. According to Quynh $\mathrm{Na}$ (2017: 8), it is said that the present author analyzed the sentence to see whether the students do not coincide with the grammatical subject or where both the topic and the subject are dropped. Sentences can be analyzed to see if students tend to make mistakes in translation due to the grammatical subject and subject matter imprecision.

Based on the results of research conducted by Teodora Popesc (2013: 243) that identified three types of errors: a) interference errors generated by L1 transfer; b) intralingual errors which result from incorrect (incomplete or overgeneralised) application of language rules; c) developmental errors caused by the construction of faulty hypotheses in L2.

Errors can be identified into three types of errors such as; mistakes in understanding the first language, errors in the application of language rules, errors in determining the second language hypothesis.

In addition to the errors previously described, there are also errors related to the skills in the translation process ie translator error in the use of language styles. According to Wongranu (2017: 118), it is said that:

Categorized the errors into three types: semantic errors, syntactic errors, and cultural errors. Semantic errors deal with any mistranslation of words, which can be a single word, collocations, or idioms. Syntactic errors refer to mistranslation of sentence structures or grammatical structures. Cultural errors are any errors that are caused by cultural differences.

There are three types of errors: semantic error, syntax error, and cultural error. The semantic error relates to errors in understanding words or idioms, syntactic errors refer to errors in translating sentences, structures or grammatical structures. The cultural error is a mistake in understanding the culture of speakers caused by cultural differences.

Moentaha (2006: 22) that mistakes in translation can be divided into two parts, namely; First, the lexical error is that the meaning system of words in a language (source language) is usually not entirely the same as the equivalent word meaning system in another language (target language). Second, the grammatical error is the difference in the structure or grammatical system of a language with another language.

Llach (2011: 75) states that the lexical error is divided into two types, namely error form, and error meaning. Form errors are errors related to writing and phonology. While the error of meaning is an error associated with the selection of the wrong word.

The lexical error is According to El-Farahaty (2016: 482 ) it is said that lexical items of different cultures may have different functions and meanings. The lexical items can be cultural differences so they have different meanings and functions. While Nida (1963: 3) states that the morphology is a field that studies the morphemes and arrangement in the formation of words. Furthermore, according to Chaer (2007: 206) that syntax is a branch of linguistics that examines the 
structure and elements of sentence formation, and also examines the units in the form of words, phrases, clauses, sentences, and discourse. Syntax is one of the areas of study in linguistics.

\section{Factors Cause Errors in Translation}

Errors committed by the translator, not solely done without any factor. A linguistic error is caused by a translator's ignorance of the translated language (source language). According to Wongranu (2017: 118), it is said that translation errors stem from various causes, such as a lack of comprehension, or misuse of words. One of the causes of mistranslation is misunderstanding and abuse of words. Factors lacking the capabilities of intelligent devices and practical tools of translators can also be a factor in a translation error.

Scientific Text

Text is a collection of several paragraphs that are interconnected with each other and usually, talk about a common topic. Because the topic of a text is usually general and complex, the discussion becomes very long and requires more than one page. In fact, not infrequently a text is eventually compiled and published by a particular publishing institution into a journal, bulletin, or book.

According to Brown (2001: 141) that the text is all kinds of linguistic forms, both written and oral. Thus the text coverage is very broad. Written text can include parts of tables, labels, forms, graphs up to essays, and books. While oral text may include any oral information.

Based on the results of research conducted by Larisa Ilynskaa et. al (2016: 90) it is said that the interpretation of information encoded in scientific texts may lead to the constant nature of contemporary texts, blurred boundaries between genes and complicated information structure. Interpretation of information encoded in scientific texts can potentially pose a challenge for several reasons such as changing the nature of the text, and the structure of information.

\section{METHODOLOGY}

The method used in this research is qualitative research method with content analysis approach. This research was conducted at HKBP Nommensen Pematangsiantar University in the 6th semester English education program. The data source of this research is the students of semester VI which amounted to 225 people, spread in 5 classes. Where in 1 class consists of 44-45 students. But researchers only take $25 \%$ of the total number of students, which is 55 students as research subjects to be given different texts and the text of the results of the translation of the students was made into research data.

\section{RESULTS AND DISCUSSION}

\section{A. Translation Strategy}

The translation strategy applied to the sixth-semester students of the University of HKBP Nommensen Pematangsiantar, Medan-Sumatera Utara included structural strategies (additions, transpositions) and semantic strategies (levies, deletions, and modulations). Among the strategies implemented, the majority of students use semantic strategies, especially modulation. This is because the student translates the source language text too literally and does not understand the source language text so that its equivalent is still tied to the word and source language structure, finally the resulting translation text is still ambiguous or chaotic. And the least-used translation strategy used by students is a special structural strategy of addition. This is because students translate free-language source texts that are oriented towards the target language and do not understand the source language text so that the resulting translated text is fatal.

\section{B. Lexical error}

There are two forms of lexical errors such as wrong error selection and misdirection of meaning. Among the lexical mistakes, the majority of students make mistakes related to word selection. This is because students do not understand the context of the source language text and choose the meaning of words that are too literal so that the resulting text translation is still ambiguous. And the least of lexical mistakes are the word meaningless deviations. This is because students are less likely to use referral sources such as dictionaries and translator machines so that they translate free source language texts that are oriented towards the target language, so the resulting text translates into an error of improper meaning.

\section{Morphological Error}

Special morphological errors in the field of affliction are divided into two parts: affixes that are melted, not melted and the use of improper affixation. Among these morphological errors, the majority make mistakes in the inappropriate use of affixation. This is because students do not master the structure of the source language and the target language, and do not understand the context of the translated text or source language so that the resulting translated text is still ambiguous. Meanwhile, the fewest morphological errors of affixation are yielded but not melted. This is because the students do not master the structure of the target language so that the resulting translation text has a fatal error.

\section{Syntax Errors}

From the aspect of syntactical error is divided into several kinds of errors such as; phrase field error (incomplete phrase structure), clause field error (addition of auxiliary verbs in the equational or nominal clause, separation of the actor (subject) and verb in the active clause), and sentence error (unadjusted sentence, use of 
subject redundant use of multiple connecting words in compound sentences, illogical use of phrases, improper use of couples, and redundancy of sentences).

The syntax error is that majority students make mistakes in the use of illogical sentences. This is because the student does not understand the context of the source language text (the translated text), does not understand the structure of the source language and the target language, and is unable to compose the target language sent grammatically so that the resulting translated text is not logical. Meanwhile, the least syntactic error is the addition of auxiliary verbs in the equational or nominal clause, the separation of the offender (subject) and the verb in the active clause, excessive use of the subject, and inappropriate use of the liaison in pairs. This is because students do not understand the structure of the target language is the Indonesian language.

\section{E. Factors Cause Errors in Translation}

Factors causing errors found in the text of the results of the translation of the students are: not understanding the source language text, unable to compose the target language sentences grammatically, not using reference sources such as dictionaries and translator engine, the level of quality of source language using grammatical not true, sentence (blurred), the use of ideas is not coherent and a lot of punctuation.

Among the factors causing errors in translation that the majority of students do not understand the text of the source language. This is because the lack of vocabulary does not understand the source language context. Meanwhile, the factor of error in the least translation is the level of the quality of the source language using the incorrect grammatical, the sentence is taxa (blurred), the use of the idea is not coherent and many punctuations. The factor causing this error is because the source language structure is not grammatical.

\section{CONCLUSION}

Based on the research findings it can be concluded that (1) translation strategy, the majority of students use semantic strategy especially modulation in translating scientific texts and at least used the special structural strategy of addition, (2) lexical error, majority of students make formal lexical errors in word selection (3) morphological errors, the majority of students make mistakes in the affixation field of improper use of affixation and the least of which is the affixation that is not crushed but not melted, (4) syntactic errors, syntax errors found in the translation of scientific texts in fields, phrases, clauses and sentences but the majority of students make mistakes in the field of sentences that are the use of illogical phrases and the fewest errors in the field of clause is the addition of auxiliary verbs in the equational or nominal clause, and $\mathrm{m} \mathrm{I}$ (the subject) and the verb in the active clause, (5) the factor causing errors in translation ie the majority of students do not understand the text of the source language and the least of which is the quality of the source language using incorrect grammatical, the sentence is vague, the idea is not coherent and a lot of fungtuation.

\section{REFERENCES}

Al-Amer, Rasmieh et. al, (2015). Language translation challenges with Arabic speakers participating in qualitative research studies. International Journal of Nursing Studies.

Brown, H. Douglas. (2001). Teaching by Principle: An Interactive Approach to Language Pedagogy. Second Edition. New York: Longman Pearson Education Company.

Chaer, Abdul. (2007). Linguistik Umum: Edisi Ketiga. Jakarta: PT. Rinneka Cipta.

El-Farahaty, Hanem. (2016). Translating Lexical Legal Terms Between English and Arabic. Semiot Law.

Ilynskaa, Larisa et. al. (2016). Rhetoric of scientific text translation, Procedia - Social and Behavioral Sciences, 231.

Jost, Lea B. et. al. (2017). Behavioral and Electrophysiological Signatures Of Word Translation Processes. International Journal Neuropsychologia.

Kardimin. (2013). Pintar Menerjemah: Wawasan Teoritik dan Praktek. Yogyakarta: Pustaka Pelajar.

Llach, Maria Pilar Agustin. (2011). Lexical Errors and Accuracy in Foreign Language Writing. UK: Multilingual Matters.

Moentaha, Salihen. (2006). Bahasa dan Terjemahan (Bekasi: Kesaint Blanc.

Munday, Jeremy. (2008). Introducing Translation Studies: Theories and Application. New York: Routledge.

Nefedovaa, Liliya A. Irina N. Remkhe. (2014). Towards Cognitive Modelling of the Technical Translation, International Journal Process. Procedia - Social and Behavioral Sciences, 154.

Nida, Eugene A. (1963). Morfilogy of Word. Michigan: University of Michigan Press.

Popesc, Teodora. (2013). A Corpus-based approach to translation error analysis. A case-study of Romanian EFL learners. Procedia - Social and Behavioral Sciences, 83.

Porta, Jordi et. al. (2014). A rule-based translation from written Spanish to Spanish Sign Language glosses. International Journal Computer Speech and Language, 28.

Quynh Na, Pham Phu. (2017). errors in the translation of topic-comment structures of Vietnamese into English. Asian EFL Journal. 
Journal of Education, Teaching and Learning

Volume 3 Number 1 March 2018. Page 23-27

p-ISSN: 2477-5924 e-ISSN: 2477-8478

Wongranu, Pattanapong. (2017). Errors in translation made by English major students: A study on types and causes. Kasetsart Journal of Social Sciences, 38 